\title{
Chocolate rheology
}

\author{
Reologia de chocolate
}

\section{Estela Vidal GONÇALVES ${ }^{1}$, Suzana Caetano da Silva LANNES ${ }^{1 *}$}

\begin{abstract}
Rheology is the science that studies the deformation and flow of solids and fluids under the influence of mechanical forces. The rheological measures of a product in the stage of manufacture can be useful in quality control. The microstructure of a product can also be correlated with its rheological behavior allowing for the development of new materials. Rheometry permits attainment of rheological equations applied in process engineering, particularly unit operations that involve heat and mass transfer. Consumer demands make it possible to obtain a product that complies with these requirements. Chocolate industries work with products in a liquid phase in conching, tempering, and also during pumping operations. A good design of each type of equipment is essential for optimum processing. In the design of every process, it is necessary to know the physical characteristics of the product. The rheological behavior of chocolate can help to know the characteristics of application of the product and its consumers. Foods are generally in a metastable state. Their texture depends on the structural changes that occur during processing. Molten chocolate is a suspension with properties that are strongly affected by particle characteristics including not only the dispersed particles but also the fat crystals formed during chocolate cooling and solidification. Chocolate rheology is extensively studied, and it is known that chocolate texture and stability is strongly affected by the presence of specific crystals.
\end{abstract}

Keywords: rheology; texture; chocolate.

\section{Resumo}

Reologia é a ciência que estuda a deformação e fluxo de sólidos e fluidos sob a influência de forças mecânicas. As determinações reológicas de um produto no estágio de produção podem ser úteis no controle de qualidade. A microestrutura de um produto pode ser correlacionada com o comportamento reológico, permitindo desenvolver novos materiais. A reometria permite a aplicação de equações reológicas em processos de engenharia, particularmente nas operações unitárias que envolvem aquecimento e transferência de massa. A demanda dos consumidores torna possível obter um produto que esteja de acordo com as necessidades. As indústrias de chocolates trabalham com o produto na fase líquida na concha, na temperadeira e também durante o bombeamento. O desenho de cada tipo de equipamento é essencial para o ótimo processamento. No desenho de cada processo é necessário conhecer as características físicas do produto. O comportamento reológico do chocolate pode auxiliar no conhecimento das características de aplicação e dos consumidores do produto. Alimentos estão geralmente em estado metaestável. Sua textura depende das trocas estruturais que ocorrem com seu processamento. Chocolate líquido é uma suspensão com propriedades que são fortemente afetadas pelas características das partículas, incluindo não somente partículas dispersas mas também cristais de gordura formados durante o resfriamento e solidificação. A reologia de chocolates é extensivamente estudada, a textura do chocolate e sua estabilidade são fortemente afetadas pela presença de cristais específicos.

Palavras-chave: reologia; textura; chocolate.

\section{Introduction}

Chocolate can be described as a suspension consisting of nonfat particles (sugar and cocoa solids and, eventually, milk powder particles) dispersed in cocoa butter as a continuous phase (BECKETT, 2009b; SCHANTZ; ROHM, 2005; SOKMENS; GUNES, 2006). Molten chocolates represent a dense blend of phospholipid-coated sucrose and cocoa particles in liquid fat.

The characteristic flavor of chocolate has to be developed in several processing steps. During processing, the components are mixed, refined, and conched to attain desired rheological properties for a final defined product texture and melting characteristics. A conche is a scraped-surface mixer that optimizes flavor development and turns chocolate mass into a flowable liquid. Through shear and longitudinal mixing, acidic flavors and moisture in the cocoa mass are reduced. Upon entering the conche, not all sugar and cocoa particles will be coated with cocoa butter. Fat in the chocolate will be released from the agglomerated chocolate mass and spread to cover these particles so that they can flow easily. The final chocolate mass viscosity should be deemed optimal for the ensuing tempering (AFOAKWA et al., 2008).

Milk chocolate usually contains about $12 \mathrm{~g}$ of cocoa mass, $19 \mathrm{~g}$ whole milk powder, $48.5 \mathrm{~g}$ sugar and, additionally, $20 \mathrm{~g}$ added cocoa butter per $100 \mathrm{~g}$ chocolate (BECKETT, 2009b; SCHANTZ; ROHM, 2005). Total solid content of chocolates varies from 65 to $75 \%$ depending on market requirement, and about $20 \%$ is milk powder content in milk chocolates (AFOAKWA et al., 2008;

Recebido para publicação em 24/5/2010

Aceito para publicação em 18/11/2010 (004857)

${ }^{1}$ Biochemical-Pharmaceutical Technology Dept., Pharmaceutical Sciences School, University of São Paulo - USP, Av. Prof. Lineu Prestes, $n$. 580, CEP 05508900,

São Paulo - SP, Brasil,E-mail: scslan@usp.com

${ }^{*}$ A quem a correspondência deve ser enviada 
LUCISANO; CASIRAGHI; MARIOTTI, 2006). This amount of milk powder affects the sensory characteristics of the final product, the processing behavior, and the rheological properties of fluid chocolate mass (TAYLOR, 2009)

The flow properties of chocolate are important because the quality control of the product is a necessity. If viscosity is too low, the weight of the chocolate over the enrobed candy will also be too low. When it is too high, bubbles may be formed and ithey that not come out of the chocolate molded tablet. Also, the flavor of a chocolate in the mouth is also affected by viscosity; therefore, incorrect flow properties can be perceived by the consumer. The perceived taste depends upon the order and rate of contact, which are related to the viscosity and rate of melt. Chocolates stored in the refrigerator or in a warm room present different flavors (BECKETT, 2009b).

Chocolate rheology is usually quantified in manufacturing processes using two parameters: yield stress and apparent (plastic) viscosity. Yield stress is a material property which denotes the transition between pseudo-solid and pseudo-liquid behaviors - related to minimum shear stress at first evidence of flow - or transition from elastic to viscous deformation. Plastic viscosity determines pumping characteristics, filling of rough surfaces, coating, and sensory character of chocolate mass. Some studies have found that chocolates of high viscosity have a pasty mouth-feel which lasts longer in the mouth and stated that viscosity is related to particle size distribution, composition, and processing strategy.

The determination of rheological properties of chocolate is important in manufacturing processes for obtaining highquality products with well-defined texture. Factors such as fat content, particle size distribution, moisture content, emulsifiers, conching time, and temperature affect rheological properties and the production cost. Molten chocolate is a non-Newtonian fluid with an apparent yield stress, and it can be described by a number of mathematical models such as Bingham, HerschelBulkley, and Casson models (SOKMENS; GUNES, 2006). In the actual praxis, one carries out measurement of equilibrium flow curves at controlled shear rate according to OICCC (International Office of Cocoa, Chocolate and Confectionery) standard or Tscheuschner depending on interesting parameter (RHEOTEST, 2010).

Since 1973, the International Confectionery Association (ICA) has accepted that rheological measurements of molten chocolate can be taken using rotational viscometers with concentric cylinders (bob and cup geometry) and the calculation of the parameters can be carrue ot using the Casson equation. In 2000, the ICA recommended measurement of stress and viscosity at shear rates between 2 and $50 \mathrm{~s}^{-1}$ using up and down curves in shear rate preceded by a pre-shear at $5 \mathrm{~s}^{-1}$ lasting 5 minutes (AFOAKWA et al., 2009).

The Casson model is a well-known and the most used rheological model for describing the non-Newtonian flow behavior of fluids with a yield stress. The model was developed for viscous suspensions of cylindrical particles. Some fluids are particularly well described by this model because of their nonlinear yield-stress-pseudoplastic nature and chocolate is among those fluids. Due to the non-Newtonian characteristic of chocolates, the shear rate (and consequently the viscosity) needs to be corrected for any geometry used to make the measurements, except for those made in an "absolute" viscometer, of which the cone-and-plate and the torsional plate are the only examples. The narrow-gap Couette viscometer is a close approximation, which requires a fine hand to set up, is prone to operator error, and is not usually indicated for industrial situations. Yield stress can be obtained by independent methods or by extrapolation to zero shear rate, and it does not require a shear rate correction (JOYE, 2003).

Afoakwa et al. (2009) investigated the relationship between the Casson model and the International Confectionery Association (ICA) recommendations. The ICA accepts rheological measurement of molten chocolate using rotational viscometers with concentric cylinders (bob and cup geometry) and the use of Casson equation by interpolating data for chocolate viscosity. In the United States, the current Chocolate Manufacturers Association (CMA) method for determining chocolate rheological properties is to extrapolate concentric cylinder flow data using the Casson equation and the vane technique rather than Couette geometry, which conflicts with the ICA quantification strategy. The relationship was calculated using correlation analysis between Casson plastic viscosity and Casson yield value, apparent viscosity, and yield stress. High correlation coefficients were observed between Casson plastic viscosity and apparent viscosity, and also between Casson yield value and yield stress. The other results also showed high correlations for Casson plastic viscosity and Casson yield value and for yield stress and apparent viscosity as well. Both interpolation and extrapolation data are used to characterize thixotropy, but no certified method has been denoted. All those high correlations obtained showed that the rheological parameters were very closely related to the particle size distribution, fat, and lecithin content, their key influencing factors. In addition, the high correlation between the two strategies was closely related suggesting that both techniques could be used independently to evaluate the rheological properties of dark chocolates.

Joye (2003) developed a shear rate and viscosity correction factors for a Casson fluid in cylindrical (Couette) geometries. The cone-and-plate system was used. The data from the Brookfield viscometer was converted to shear stress and the speed converted into shear rate. In this case, the shear rate assumes Newtonian behavior. Each data points obtained from Brookfield geometry - trough the ramp shear rates up and down - had a corresponding corrected point. Except for the low-shear-rate region, where shear stress is close to yield stress and data is unreliable due to the more than $30 \%$ error rate, the correction factors tested showed very good agreement with viscosity-shear rate obtained in an "absolute" viscometer (coneand-plate) at higher shear rates.

Servais, Ranc and Roberts (2003) proposed a new reference method for the viscosity of chocolate and related cocoa products measurements using factory grade viscometers. The new method requires the value of the stress at a shear rate of $5 \mathrm{~s}^{-1}$ to represent the yield stress of chocolate, the value of the viscosity 
at a shear rate of $40 \mathrm{~s}^{-1}$ to represent the high shear viscosity, and the difference between the viscosity measured at a shear rate of 40 during the ramp up and down in shear rate to represent thixotropy. The results were related to the solid to liquid glass transition of dispersions under applied stress, and it was shown that the stress induced formation and rupture of aggregates for particles in colloidal suspensions with low interaction energy.

Gotz, Balzer and Hinrichs (2005) characterized the structure and flow behavior of chocolate using Nuclear Magnetic Resonance (NMR) model systems and rheometry. Based on the correlation between NMR flow functions and rotational/ capillary rheometry, it was possible to determine characteristic viscosities of chocolate masses by means of NMR-relaxation experiments, which is important to allow the employment of an automation control process. This NMR application with comparatively short measuring times is especially interesting for disperse systems, in which the use of conventional rheometric techniques may cause large errors. The only prerequisite for the measurement of the viscosities using NMR is a previous calibration. The NMR self-diffusion experiments are especially appropriate to characterize the influence of emulsifiers on the structure and the flow behavior of chocolate masses.

Wichchukit, McCarthy and McCarthy (2005) studied rheological properties, especially shear viscosity and yield stress, of molten milk chocolate during steady pipe flow using a Magnetic Resonance Imaging (MRI) viscometric method. The experimental method combines shear rate values obtained from an MR velocity image and shear stress values obtained from an independent pressure drop measurement. The results were compared with the emulsifier type and emulsifier level used on the formulation. The rheogram data were fit by the Casson model to yield the Casson yield stress and plastic viscosity. The rheological parameters were incorporated into a drainage theory model to predict coating thicknesses in the enrobing process.

Benkhelife, Alvarez and Flick (2008) showed the feasibility of using the scraper-rheometer to obtain rheological data for standard Newtonian and non-Newtonian fluids, once rheological data can be missed for products subjected to an industrial thermal treatment and particularly when phase transition occurs inside the equipment, such as crystallization. A small scraper-rheometer composed of a cylindrical cup of $0.1 \mathrm{~L}$ equipped with a vessel jacket and electrical heaters for temperature control was used. The scraper, driven by a variable speed motor and controlled by a non-contact type tachymeter, consists of four blades located at $1 \mathrm{~mm}$ from the wall. The scraping system is then connected to a rotational viscometer. Two cylindrical PVC bobs have been specially developed and can be placed in the middle of the scraper. Scraper and bob rotate in opposite directions. For each tested fluid, the torque is measured on the bob as a function of the rotational speed. The mean difference between the viscosities found in classical viscometer and in the scraper-rheometer is equal to $8 \%$, which can be considered acceptable.

Gabriele et al. (2008) proposed to characterize chocolate samples at typical process temperatures (approximately $30^{\circ} \mathrm{C}$ ) with analysis of compliance, as a function of time, given enough time to evaluate a material "elasticity" related to the solid-like behavior of the material. Moreover, a specific time dependent elasticity was defined as the ratio between the differential area, in a time range, and total area. The samples were formulated containing several levels of fat content and were conditioned directly on the rheometer plate by applying two different controlled cooling rates by applying a low stress to ensure material linear behavior. The experimental data were analyzed by the proposed method, and the specific elasticity was related to single crystal properties. It was found that the fat crystal amount and its properties depend on the fat content and cooling rate differently; moreover creep proved to be able to detect even small differences among tested samples.

Baker, Brown and Anantheswaran (2006) tested the controlled stress vane method to measure the yield stress in dark chocolate formulations using vanes with different ratios and different stress rates. When the vane displacement data were transformed into a ratio of vane velocity to elapsed time, the square root of vane velocity (SV) or the cube root of displacement, a definite yield phenomenon was observed. The linear regression of SV derived yield stress on vane dimensions, stress rate and chocolate particle size. The value of the yield stress was the least when determined for a vane height to diameter ratio of 2 and at a stress rate of $3 \mathrm{~Pa} /$ minutes using the SV transformation.

Briggs and Wang (2004) investigated the feasibility of traditional rheological methods, such as that by Casson and Herschel-Bulkley, to determine the influence of shearing rate and tempering time on the flow behavior of milk chocolate during the tempering process. Rotational rheometer studies were conducted with a parallel-plate sensor. To investigate the influence of tempering on the flow behavior of chocolate, a steady-shear flow was analyzed by increasing the shear rate linearly from 0 to $100 \mathrm{~s}^{-1}$. Shear stress vs. shear rate data was fit with the Casson and Herschel-Bulkley constitutive equations. According to the results obtained, they concluded that HerschelBulkley model is a good option to evaluate chocolate rheology and crystallization behavior as an alternative to Casson's model, but further studies are needed.

Vivar-Vera et al. (2008) studied the rheological properties of dark chocolate mass during conching using a mixing rheometry approach. A helical ribbon impeller fitted to a rheometer was used to estimate viscous properties as a function of power process parameters. Torque and rotational velocity data were transformed into power consumption curves and into process viscosities. In addition, Scanning Electron Microscopy (SEM) was used to assess structural changes in the mass at different conching temperatures and rotor speeds. Mass samples showed a strong shear thinning behavior which increased with conching time under all conching conditions tested. Conching at $60^{\circ} \mathrm{C}$ instead of $40^{\circ} \mathrm{C}$ - produced less viscous and more pseudoplastic masses, which improves flow properties of dark chocolate. Increasing speed from 0.66 to $1 \mathrm{~s}^{-1}$ did not affect shear thinning behavior but contributed to decrease the consistency index of the mass during the first half of conching. Increasing temperature and speed reduced conching time and increased smoothness in the final product. 
Afoakwa et al. (2008) investigated the relationship between melting properties, texture, and rheology of dark chocolate according to the particle size distribution and solids profile. The rheological measurements indicated that yield stress and apparent viscosity follow the same trend and have a strong linear correlation with high significance coefficient, which means that any of these rheological parameters could predict the rheological behavior of chocolate during manufacture. They proposed a correlation between rheological and textural properties using the principal component analysis, which can be useful to predict melting duration in new product development and process purposes.

Physical and textural properties are important to be studied because they can help to classify the product and also because they affect food behavior during processing, storage, packing, handling, and consumption (EDUARDO; LANNES, 2007). The back extrusion technique requires simple and usually readily available equipment (OSORIO; STEFFE, 1991). During the back extrusion test, a cylindrical plunger is stressed down into the fluid, and it flows upwards through a concentric annular space (PIAZZA et al., 2009). The results of the back extrusion tests are plotted in a graph force $(\mathrm{N})$ vs. time (second), and a typical curve describes both the compaction/penetration in the sample and the extrusion. Gonçalves and Lannes (2010) applied texture analysis plus back-extrusion system aiming at chocolate products design.

Therefore, rheological properties are mainly influenced by particle size distribution and ingredients composition, which in turn affects final texture and melting profile and also plays a significant role on process in industry. Most of the solid ingredients are about $1 \mathrm{~mm}$ or more in diameter. The tongue will detect particles larger than $0.03 \mathrm{~mm}$, and the chocolate will appear to be gritty. Often, milling produces a lot of very fine particles of less than $0.005 \mathrm{~mm}$ in size. The surface of these particles needs to be coated with fat to make them flow because unless extra fat is added the chocolate becomes highly viscous and tends to melt less easily, often remaining in the mouth with a slightly clay-like texture (BECKETT, 2009a).

The crystallization state of the sugars in the finished crumb is very important. The ultimate aim is to crystallize both the sucrose and lactose as fully as possible. The benefits of a highly crystalline crumb are that since very little amorphous glassy sugar remains to trap fat, less fat needs to be used to make the correct finished chocolate viscosity. Below the glass transition temperature for sucrose in water, viscosity is so high that many crystal nuclei are able to grow. The subsequent liberation of fat from the amorphous sugar can lead to easier processing into chocolate with less total fat being used to reach the required chocolate viscosity. When liquor is to be incorporated into chocolate, it is advisable to grind nib to the desired end fineness for organoleptic considerations. This assures maximum free fat, minimum viscosity, and appropriate texture and flavor. In chocolate processing, it could be recommended milling nib to an end fineness $2-5 \mu \mathrm{m}$ less than the end fineness of the finished chocolate. This is said to reduce subsequent refiner wear, increase refiner through put, and improve finished product flow properties, which is lower in viscosity. As the grinding temperature exceeds the glass transition temperature, either because the roll temperature increases or the glass transition temperature decreases, say because of an increase in moisture content, spray-dried whole milk particles deform plastically. These highly asymmetric particles have a deleterious effect on the product viscosity and sensory properties (SERVAIS; RANC; ROBERTS, 2003; BECKETT, 2009b).

Temperature has a significant effect on the rheology of the chocolate film and thus influences the refining process. Temperature is maintained by circulating water in the interior of each roll. The relative size of the cooling zone (1/2 the circumference of the roll) compared to the gap width (a few $\mu \mathrm{m}$ ) allows for effective temperature control. The properties of the material being broken may change substantially with temperature and thereby alter the milling process. The proper consistency for transferring the product from roll-to-roll is maintained by the appropriate fat content. It is normally advantageous to roll refine chocolate at the lowest fat content possible - in the range of $24-27 \%$. It is said that $1 / 2$ of all the fat conserved at the refining step is saved during conching, i.e. if you reduce the fat at refining by $1 \%$, you only need to put $0.5 \%$ into the masse at the end of conching to obtain the same viscosity. As stated earlier, a material's tendency to agglomerate rises with smaller particle size and moisture content. Refining a very low-fat mixture, especially under humid conditions, can result in particle agglomerates exiting the roll refiner. For accurate particle size control, it is necessary to produce consistent and uniform feed material, which can be produced by intense mixing prior to refining, or perhaps even better by the two-stage refining process (BECKETT, 2009b).

Studies correlating chocolate composition and textural or rheological properties are commonly found due to the source of new fat or cocoa butter replacers which strongly affect rheological parameters on chocolate manufacture and final product texture. According to that, adaptations on manufacturing scale have to be done in order to keep the desirable sensory characteristics in the final product. Rheology is a useful feature on setting those issues. Several works have been conducted to study and understand rheological properties of chocolates.

The various fats used in chocolate can contain different levels of trisaturated triglycerides. Since these can crystallize out early in the tempering process, they can, in some instances, have an effect on the rheology of the chocolate. Six basic source oils are permitted as non-cocoa vegetable fats (CBE - Cocoa Butter Equivalent) in chocolate throughout European Union palm oil, shea oil, illipe butter, sal oil, kokum gurgi, and mango kernel oil. Among these six oils, four (palm, shea, sal, and mango kernel) usually have to undergo some form of fractionation process to concentrate the SOS type of triglyceride necessary for equivalence to cocoa butter. Palm oil is even more complicated since it contains a significant quantity of trisaturated triglycerides which also have to be removed. Maheshwari and Reddy (2005) investigated the incorporation of kokum fat (Vateria indica) as a cocoa butter improver in chocolate formulations due to its high content of stearic acid, which can be useful to increase the solid content, to raise the melting point, and also to decrease the tempering time. The effect of the various levels of replacement 
on chocolate quality was studied. The viscosity of the chocolate mass after conching was measured using rotational viscometer with coaxial cylinder. Both shear stress and viscosity were measured at each shear rate and from these values. Casson plastic viscosity and Casson yield stress (yield value) were calculated using computer software. The results showed that the milk chocolate formulated using $18.2 \%$ of kokum fat (on product basis) had a significant increase in shear stress and viscosity compared with those of milk chocolate prepared with lower levels of kokum fat. This was reflected on plastic viscosity and yield stress, and may be due to the crystallization of kokum fat at $30^{\circ} \mathrm{C}$, which was not significant at lower proportions and was approved as the best cocoa butter.

Schantz and Rohm (2005) determined the effects of different and varied mixtures of lecithin and polyglycerol polyricinoleate (PGPR) on the flow parameters of melted chocolate in order to obtain the optimum emulsifier blend. The sample was adjusted to $40{ }^{\circ} \mathrm{C}$ for 10 minutes. After 6 minutes of preshearing at 200 and $150 \mathrm{~s}^{-1}$ for dark and milk chocolate, respectively, the shear rate was reduced to $0.1 \mathrm{~s}^{-1}$ within 10 minutes in a logarithmic ramp, and it was then kept constant at $0.1 \mathrm{~s}^{-1}$ for 1 minute. Shear stress was recorded as a function of shear rate and time. A unique mathematical model such as Herschel-Bulkley or Casson is unsatisfactory when the flow curves shapes are different according to the product composition.

The averaged shear stress within the last minute of preshearing was used, divided by the applied shear rate, as a direct measure of equilibrium viscosity. Yield stress was calculated from the mean shear stress measured after applying a shear rate of $0.1 \mathrm{~s}^{-1}$ for 1 minute. In case of sticky masses, such as masses without emulsifier or with low emulsifier content, the yield stress was calculated from the bending point in the flow curve, which usually appeared in a shear rate range between 0.1 and $1 \mathrm{~s}^{-1}$. According to each specific need for processing the chocolate products, the flow properties can be easily handled using rheological features to obtain the desirable characteristics.

Nebesny and Dorota (2005) studied the effect of soybean lecithin content on the properties of sucrose-free, dark, and milk chocolate masses sweetened with isomalt and aspartame also comparing to sucrose-containing chocolate masses. Using a rheoviscosimeter equipped with the co-axial rotor and stator, Casson viscosity and yield value were determined. Dark and milk chocolate masses sweetened with isomalt presented higher Casson viscosity than that of the sucrose containing chocolate. An increase in the lecithin content from 0.1 to $1.0 \mathrm{~g} .100 \mathrm{~g}^{-1}$ resulted in a drop in Casson viscosity in all types of chocolate mass studied. A considerable decrease in Casson viscosity of dark and milk chocolate masses supplemented with isomalt was observed when the lecithin concentration was gradually elevated to $0.5 \mathrm{~g} .100 \mathrm{~g} \mathrm{~g}^{-1}$. As with the control, the sucrosecontaining milk chocolate masses, the greatest drop in Casson viscosity occurred within lecithin concentrations ranging up to $0.3 \mathrm{~g} .100 \mathrm{~g}^{-1}$. The results showed a stronger impact of lecithin on Casson yield values than on Casson viscosity, regardless the chocolate mass formulation (sucrose-free, traditional, milk or dark). The overdose of this emulsifier caused both worse sensory and flow properties of these masses.
The influence of the sucrose mono-ester in different levels, alone or in combination with lecithin on rheological parameters of milk chocolate, was showed by Swer and Reddy (2008). Sucrose mono-ester has shown a lecithin-like behavior, which means it decreased the viscosity of chocolate to $40{ }^{\circ} \mathrm{C}$. When a greater amount of sucrose mono-ester was added, from 0.5 to $1.5 \%$, viscosity and shear stress also decreased, but at $2 \%$ they increased the viscosity significantly. When sucrose mono-ester was added with lecithin, it showed lower viscosity compared to individual components. Chocolate with sucrose mono-ester lowered Casson plastic viscosity and increased yield stress compared to lecithin.

Nebesny et al. (2005) developed a sucrose-free chocolate formulation containing live cells of lactic acid bacteria. The new products were tested for physicochemical properties using the OICCC method for the determination of Casson viscosity in the range of shear rates from 5 to $601 \mathrm{~s} \mathrm{~s}^{-1}$ using a rheoviscosimeter with a coaxial rotor and stator. When added to chocolate masses, the powered yoghurts containing the viable cells widely affect the rheological attributes such as Casson plastic viscosity and yield value. The results obtained in the rheological tests indicated that the addition of yoghurt to the chocolate masses increased the Casson viscosity and yield value, and that the product presented a thickening behavior in comparison to the yoghurt-free products.

Sokmen and Gunes (2006) investigated the effects of different bulk sweeteners, such as maltitol, isomalt, and xylitol and their particle size distribution on rheological properties of molten chocolates. The tests were performed using a shear rate-controlled rheometer according to the IOCCC method. Shear stress was measured as a function of an increase in the shear rate from 5 to $60 \mathrm{~s}^{-1}$ (ramp up) within 120 seconds, then by decreasing the shear rate from 60 to $5 \mathrm{~s}^{-1}$ (ramp down), taking measurement each ramp up and down. This measurement cycle was repeated 30 times consecutively until the thixotropy in the samples was eliminated. The data from the $30^{\text {th }}$ measurement were applied to Casson, Bingham, and Herschel-Bulkley models. The Herschel-Bulkley model fit the data (viscosity, yield stress, flow behavior index) more appropriately. Although Casson model is widely used and recommended by IOCCC to describe flow behavior of chocolate, it requires a lower amount of particles than that present in chocolate and therefore is unable to produce acceptable reproducibility.

Abbasi and Farzanmehr (2009) also evaluated the effects of sugar substitutes on rheological characteristics of prebiotic milk chocolate formulations containing polydextrose and maltodextrin at different levels (0-100\%) along with sucralose. All chocolates showed thixotropic and shear thinning behavior, and among the evaluated mathematical models, Casson model showed the best fitting for predicting rheological properties. The chocolate formulations containing high levels of sugar substitutes had higher moisture content, Casson viscosity, and yield stress than the those of the control. In contrast, the lowest moisture content, as well as Casson viscosity and yield stress were observed with moderate amounts.

Samples of low-sugar milk chocolate with prebiotic properties with several different levels of inulin, polydextrose, 
and maltodextrin along with sucralose $(0.04 \% \mathrm{w} / \mathrm{w})$ were used instead of sugar. In the physical analyses, formulations with high ratios of polydextrose and maltodextrin were moister and softer than the control. The lowest moisture content and highest hardness were observed for the moderate ratios. The findings showed that the use of prebiotic ingredients instead of sugar could lead to production of low-calorie milk chocolate without having the undesirable textural and physiological effects on the product and consumers (FARZANMHER; ABBASI, 2009).

Lucisano, Casiraghi and Mariotti (2006) evaluated the effect of the addition of dried milk and milk at different times during the refining process on the rheological properties of chocolate with a coaxial cylinder system. Samples of melted chocolate in the refining process were conditioned at $40{ }^{\circ} \mathrm{C}$, and a shear rate varying from 0.232 to 46.1 seconds was applied. Casson's equation was the model used to determine Casson plastic viscosity and Casson yield value. Through Casson model, it was possible to evaluate data such as plastic viscosity and yield value by correlating them to the addition of the ingredients leading to an understanding of the integration between process and formulation. Milk powder able to assure a low viscosity and a low yield value at a given total fat content is particularly suitable for the production of chocolate when using the traditional technology. Processes for enhancing the milk free fat content during the spray-dried procedure have been proposed lately. The increase of the free fat content due to this processing makes the milk fat more functional in milk chocolate production by reducing the amount of cocoa butter required to obtain low viscosity.

\section{Conclusions}

Rheology evaluating is a useful feature for new product development and manufacturing control since the product composition is the main responsible for changes in flow attributes.

For several years the Casson model was the most used method to evaluate the rheological behavior of chocolates. Casson's equation derives from classical equations for flow analysis and is still widely applied on confectionary factories for being easy to handle; nevertheless it presents some limitations. In order to improve the use of this model, many researchers have been developing correction factors for Casson' model and new techniques for rheological analysis.

The Casson model's parameters can be easily obtained from simple equipment, such as viscometers and rotational rheometers. Nonetheless, more complex equipment has been designed for rheological purposes, for example an oscillatory equipment to be used alone or in combination with microscopy. The Casson model and simple viscometers are still useful due to the studies on this topic and the improvements made in the equations, which lead to more reliable results using the same basic equation with a new and different approach.

\section{References}

ABBASI, S.; FARZANMEHR, H. Optimization of the formulation of prebiotic milk chocolate based on rheological properties. Food Technology and Biotechnology, v. 47, p. 396-403, 2009.
AFOAKWA, E. O. et al. Comparison of rheological models for determining dark chocolate Viscosity. International Journal of Food Science and Technology, v. 44, p. 162-167, 2009.

AFOAKWA, E. O. et al. Relationship between rheological, textural and melting properties of dark chocolate as influenced by particle size distribution and composition. European Food Research Technology, v. 227, p. 1215-1223, 2008.

BAKER, B. S.; BROWN, B. D.; ANANTHESWARAN, R. C. Measurement of yield stress in dark chocolate using controlled stress vane method. Journal of Texture Studies, v. 37, p. 655-667, 2006.

BECKETT, S. Chocolate manufacture. In: TALBOT, G. (Ed.). Science and technology of enrobed and filled chocolate, confectionery and bakery products. Boca Raton: CRC Press, 2009a. p. 11-28.

BECKETT, S. T. The science of chocolate. 2 ed. Cambridge: Royal Society of Chemistry Paperbacks, 2009b. 240 p.

BENKHELIFE, H.; ALVAREZ, G.; FLICK, D. Development of a scraperrheometer for food applications: Rheological calibration. Journal of Food Engineering, v. 85, p. 426-434, 2008.

BRIGGS, J. L.; WANG, T. Influence of Shearing and time on the rheological properties of milk chocolate during tempering. Journal of the American Oil Chemist's Society, v. 81, n. 2, p. 117-121, 2004.

EDUARDO, M. F.; LANNES, S. C. S. Use of texture analysis to determine compaction force of powders. Journal of Food Engineering, v. 80, p. 568-572, 2007.

FARZANMEHR, H.; ABBASI, S. Effects of inulin and bulking agents on some physicochemical, textural and sensory properties of milk chocolate. Journal of Texture Studies, v. 40, p. 536-553, 2009.

GABRIELE, D. et al. Influence of fat content on chocolate rheology. In: INTERNATIONAL CONGRESS ON RHEOLOGY - THE SOCIETY OF RHEOLOGY, 15., 2008. Proceedings... p. 1265-67.

GONÇALVES, E. V.; LANNES, S. C. S. Rheological behavior of nutritional enriched chocolate. In: IUFOST CONGRESS, 2010. Proceedings... 1 CD-ROM.

GOTZ, J.; BALZER, H.; HINRICHS, R. Characterisation of the structure and flow behaviour of model chocolate systems by means of NMR and Rheology. Applied Rheology, v. 15, p. 98-111, 2005.

JOYE, D. D. Shear rate and viscosity corrections for a Casson fluid in cylindrical (Couette) geometries. Journal of Colloid and Interface Science, v. 267, p. 204-210, 2003.

LUCISANO, M.; CASIRAGHI, E.; MARIOTTI, M. Influence of formulation and processing variables on ball mill refining of milk chocolate. European Food Research Technology, v. 223, p. 797-802, 2006.

MAHESHWARI, B.; REDDY, S. Y. Application of kokum (Garcinia indica) fat as cocoa butter improver in chocolate. Journal of the Science of Food and Agriculture, v. 85, p. 135-140, 2005.

NEBESNY, E. et al. Properties of sucrose-free chocolates enriched with viable lactic acid bacteria. European Food Research Technology, v. 220, p. 358-362, 2005.

NEBESNY, E.; DOROTA, Z. Effect of lecithin concentration on properties of sucrose-free chocolate masses sweetened with isomalt. European Food Research Technology, v. 220, p. 131-135, 2005.

OSORIO, F. A.; STEFFE, J. F. Evaluating Herschel-Bulkley fluids with the back extrusion (annular pumping) technique. Rheologica Acta, v. 30, p. $549-558,1991$.

PIAZZA, L. et al. Dairy cream response in instrumental texture evaluation processed by multivariate analysis. Chemometrics and Intelligent Laboratory Systems, v. 96, p. 258-263, 2009.

RHEOTEST. Applications for laboratories and process control. Ottendorf-Okrilla, Germany. Disponível em: <http://www.rheotest. de/html_en/applications.html>. Accesso em: 03 maio 2010.

SCHANTZ, B.; ROHM, H. Influence of lecithin-PGPR blends on the rheological properties of chocolate. Lebensmittel Wissenschaft und Technologie, v. 38, p. 41-45, 2005. 
SERVAIS, C.; RANC, H.; ROBERTS, I. D. Determination of chocolate viscosity. Journal of Texture Studies, v. 34, p. 467-497, 2003.

SOKMEN, A.; GUNES, G. Influence of some bulk sweeteners on rheological properties of chocolate. LWT, v. 39, p. 1053-1058, 2006.

SWER, J. O.; REDDY, Y. S. Effect of sucrose mono-ester on rheology of chocolate. Journal of Food Science and Technology-Mysore, v. 45 , p. $447-449,2008$.
TAYLOR, J. E. et al. Shear rheology of molten crumb chocolate. Journal of Food Science, v. 74, p. 55-61, 2009.

VIVAR-VERA, G. et al. Chonching - Rheological and structural changes of chocolate mass. Deutsche Lebensmittel-Rundschau, v. 104, p. 376-382, 2008.

WICHCHUKIT, S.; McCARTHY, M. J.; MACCCARTHY, K. L. Flow behavior of milk chocolate melt and the application to coating flow. Journal of Food Science, v. 70, p. E165-E171, 2005. 